\title{
Improving Glucose Management with Point-of-Care Testing in the Emergency Department
}

\author{
Nahal Beik $\cdot$ Kimberly Terry
}

Published online: 27 June 2014

(c) Springer Science+Business Media New York 2014

\begin{abstract}
Hyperglycemic emergencies such as diabetic ketoacidosis (DKA) and hyperosmolar hyperglycemic states (HHS) have a significant impact on morbidity and mortality. Patients with type 1 and type 2 diabetes are at risk for developing these severe metabolic complications and often present to the emergency department requiring fluid management, electrolyte replacement, and insulin therapy for rapid and safe reversal. Early identification of hyperglycemic patients with the use of point-of-care (POC) testing may facilitate implementation of an institutional treatment algorithm in those patients presenting with DKA and HHS. There are limited studies evaluating the use of POC testing for early identification of hyperglycemic emergencies and the utilization of a standardized insulin protocol. The aim of this article is to review the literature evaluating POC testing and its applicability for implementation of institutional hyperglycemic emergency protocols in the emergency department.
\end{abstract}

Keywords Hyperglycemic emergency - DKA · HHS · Point-of-care · Protocols · Care pathways · Guideline . Order set $\cdot$ Emergency department

\section{Introduction}

Diabetic ketoacidosis (DKA) and hyperosmolar hyperglycemic state (HHS) are severe metabolic complications often seen in patients with type 1 and type 2 diabetes [1].

N. Beik $(\bowtie) \cdot$ K. Terry

Pharmacy Department, Brigham and Women's Hospital,

75 Francis Street, Boston, MA 02115, USA

e-mail: nbeik@partners.org
DKA is typically associated with type 1 diabetes and is most common in young diabetic patients [2]. The overall mortality rate of DKA is around $1 \%$ and higher rates are seen in patients who are elderly or those with co-morbid conditions. HHS is typically associated with type 2 diabetes and account for approximately $1 \%$ of all primary diabetic admissions. Mortality rates in HHS have been reported as high as $20 \%$ in developed countries [3]. Treatment algorithms are tools that aid in identifying and facilitate treatment in those patients experiencing DKA and HHS. Many have incorporated point-of-care (POC) testing to expedite critical laboratory results and lead to early treatment initiation [4]. While these tests have been shown to be reliable and accurate, few studies have demonstrated benefit of POC glucose measurements.

\section{Objective}

Since many patients with diabetic complications present to emergency departments (ED) for care, the aim of our article is to evaluate the literature surrounding POC testing and treatment algorithms that facilitate management of those patients with hyperglycemic emergencies.

\section{Methodology}

We completed a literature search containing the terms "point-of-care testing," "diabetic ketoacidosis," "hyperosmolar hyperglycemic state," "protocols," "care pathways", "guideline," "order set," and "emergency department." We limited our results to the last two decades and to those articles in the English language. 
Table 1 Studies of POC testing in hyperglycemic emergencies

\begin{tabular}{|c|c|c|c|c|c|}
\hline Reference & $N$ & Background & Patient population & Methods & Results \\
\hline $\begin{array}{l}\text { Lee et al. } \\
\text { [5] }\end{array}$ & $N=12$ & $\begin{array}{l}\text { Utilization of continuous } \\
\text { glucose monitoring in } \\
\text { the ED versus } \\
\text { traditional blood } \\
\text { glucose monitoring }\end{array}$ & $\begin{array}{l}\text { Patients over } 18 \text { years old who } \\
\text { visited the ED that needed } \\
\text { mechanical ventilation or } \\
\text { vasopressor support }\end{array}$ & $\begin{array}{l}\text { Prospective } \\
\text { observational } \\
\text { study }\end{array}$ & $\begin{array}{l}\text { CGMS recorded average blood } \\
\text { sugar levels every } 5 \text { min, and } \\
\text { traditional blood glucose } \\
\text { measurement was taken every } \\
\text { hour. CGMS has good clinical } \\
\text { accuracy, but limited detection of } \\
\text { hypoglycemia }\end{array}$ \\
\hline $\begin{array}{l}\text { Charles } \\
\text { et al. [6] }\end{array}$ & $N=111$ & $\begin{array}{l}\text { Evaluated the use of } \beta \text { - } \\
\text { OH as a POC test in ED } \\
\text { to distinguish DKA } \\
\text { versus uncomplicated } \\
\text { hyperglycemia }\end{array}$ & $\begin{array}{l}\text { Patients presenting to the ED with } \\
\text { capillary glucose level } \geq 252 \mathrm{mg} / \\
\mathrm{dL} \text {, history of } \mathrm{DM} \text {, current or } \\
\text { past use of oral hypoglycemic } \\
\text { agents and/or insulin, and a } \\
\text { presenting complaint suggestive } \\
\text { of hyperglycemia }\end{array}$ & $\begin{array}{l}\text { Prospective } \\
\text { observational } \\
\text { study }\end{array}$ & $\begin{array}{l}\text { Only about } 50 \% \text { of patients could } \\
\text { provide a urine sample. Urine } \\
\text { testing also had a longer turn } \\
\text { around time and was less } \\
\text { sensitive and specific than } \beta-\mathrm{OH} \\
\text { testing. Blood ketone } \\
>3.5 \mathrm{mmol} / \mathrm{L}=100 \% \\
\text { specificity and sensitivity for } \\
\text { DKA }\end{array}$ \\
\hline $\begin{array}{l}\text { Arora } \\
\text { et al. [7] }\end{array}$ & $N=54$ & $\begin{array}{l}\text { Evaluated POC } \beta-\mathrm{OH} \\
\text { values in correlation } \\
\text { with DKA severity }\end{array}$ & $\begin{array}{l}\text { Patients in the ED who met the } \\
\text { ADA criteria for DKA }\end{array}$ & $\begin{array}{l}\text { Prospective } \\
\text { observational } \\
\text { study }\end{array}$ & $\begin{array}{l}\text { POC } \beta-O H \text { values cannot reliably } \\
\text { assess DKA severity }\end{array}$ \\
\hline $\begin{array}{l}\text { Arora } \\
\text { et al. [8] }\end{array}$ & $N=54$ & $\begin{array}{l}\text { Compared } \beta \text {-OH POC to } \\
\text { urine dipstick in } \\
\text { accurately screening } \\
\text { patients for DKA }\end{array}$ & $\begin{array}{l}\text { Patients in the ED who met the } \\
\text { ADA criteria for DKA }\end{array}$ & $\begin{array}{l}\text { Prospective } \\
\text { observational } \\
\text { study }\end{array}$ & $\begin{array}{l}\text { POC } \beta-\mathrm{OH} \text { and urine dipstick are } \\
\text { equally sensitive for DKA } \\
(98.1 \%) \text {, but } \beta-\mathrm{OH} \text { is more } \\
\text { specific than urine dipstick ( } 78.6 \\
\text { vs } 35.1 \% \text { ) }\end{array}$ \\
\hline
\end{tabular}

ED Emergency department, CGMS Continuous glucose monitoring system, $P O C$ Point-of-care, LOS Length of stay, $D C$ Discharge, $\beta$ - $O H$ Betahydroxybutyrate, DKA Diabetic ketoacidosis, DM Diabetes mellitus, ADA American Diabetes Association

\section{Results}

Several studies have evaluated ED-based POC testing in DKA and HHS (Table 1). A study evaluating continuous glucose monitoring systems (CGMS) in the ED proved to have an overall clinical accuracy of $96.8 \%$ and in agreement with capillary glucose testing levels [5]. However, CGMS demonstrated limited real-time detection of hypoglycemia. In detecting hypoglycemia, CGMS had a sensitivity and positive predictive value of $33.3 \%$ and $16.7 \%$, respectively [5]. This study suggests CGMS in the ED may be beneficial in identifying hyperglycemia, however, may not be accurate in identifying hypoglycemia. Charles et al. [6] determined that a beta-hydroxybutyrate $(\beta-\mathrm{OH})$ level of $>3.5 \mathrm{mmol} / \mathrm{L}$ was $100 \%$ sensitive and specific for a diagnosis of DKA. With that, POC testing for blood ketones is a more sensitive and specific method than a urine sample for diagnosing DKA. In addition, there was a faster test turnaround time (TAT) with POC blood ketone testing. Arora et al. [7] evaluated POC testing of $\beta-\mathrm{OH}$ for assessing DKA severity. This prospective study included 54 patients with an initial diagnosis of DKA. The mean POC $\beta-\mathrm{OH}$ for the patients with DKA was $4.9 \mathrm{mmol} / \mathrm{L}$ (IQR 3.7-5.6). The correlation coefficients between $\beta-\mathrm{OH}$ and $\mathrm{pH}$, bicarbonate, and anion gap were $0.33,0.25$, and 0.16 , respectively [7]. The study concluded that POC $\beta-\mathrm{OH}$ had modest correlation to serum measurements, however, could not be used to reliably assess the severity of DKA. Arora et al. also studied the accuracy of POC testing for $\beta$ $\mathrm{OH}$ versus traditional urine dipstick. This prospective study included 54 DKA patients, meeting diagnosis criteria consistent with the American Diabetes Association (ADA), presenting to the ED. The urine dipstick had a sensitivity of $98.1 \%$ (95\% CI 90.1-100), a specificity of $35.1 \%$ (30.7-39.6), a positive predictive value of $15 \%$ (11.5-19.2), and a negative predictive value of $99.4 \%$ (96.6-100) for DKA [19]. Using the manufacturer-suggested cutoff of $>1.5 \mathrm{mmol} / \mathrm{L}, \beta-\mathrm{OH}$ had a sensitivity of $98.1 \%$ (90.1-100), a specificity of $78.6 \%$ (74.5-82.2), a positive predictive value of $34.9 \%$ (27.3-43), and a negative predictive value of $99.7 \%$ (98.5-100) for DKA [8]. The study concluded that POC $\beta-\mathrm{OH}$ and the urine dipstick are equally sensitive for detecting DKA; however, $\beta-\mathrm{OH}$ is more specific [7, 8].

Several studies have evaluated ED-based POC testing in conditions unrelated to DKA and HHS (Table 2). Sen et al. [9] compared the accuracy of quantitative D-dimer results using a POC testing device against standard laboratory testing in patients with suspected venous thromboembolism (VTE) in the ED. The results showed that there was strong evidence of POC D-dimer being sufficiently accurate to be used as a screening device. D-dimer TAT decreased by 
Table 2 Point-of-care testing strategies in the emergency department

\begin{tabular}{|c|c|c|c|c|c|}
\hline Reference & $N$ & Background & Patient population & Methods & Results \\
\hline Sen et al. [9] & $N=100$ & $\begin{array}{l}\text { Compared POC } \\
\text { vs lab d-dimer } \\
\text { testing in } \\
\text { patients with } \\
\text { suspected } \\
\text { VTE in ED }\end{array}$ & $\begin{array}{l}\text { Patients between the ages of } \\
18-89 \text { with suspected VTE } \\
\text { presenting with pleuritic } \\
\text { chest pain or leg swelling }\end{array}$ & $\begin{array}{l}\text { Prospective single center } \\
\text { diagnostic study }\end{array}$ & $\begin{array}{l}\text { POC d-dimer testing was } \\
\text { comparable with standard } \\
\text { lab testing and was } \\
\text { sufficiently accurate to be } \\
\text { used as a screening tool in } \\
\text { the emergency department } \\
\text { setting. POC testing was } \\
\text { also associated with } \\
\text { reduced turn around time } \\
\text { versus lab testing (from } \\
90 \text { to } 15 \text { min) }\end{array}$ \\
\hline $\begin{array}{l}\text { Lee- } \\
\text { Lewandrowski } \\
\text { et al. }[10]\end{array}$ & $N=369$ & $\begin{array}{l}\text { Impact of POC } \\
\text { testing in the } \\
\text { ED }\end{array}$ & $\begin{array}{l}\text { Patients in the ED of a large } \\
\text { academic medical center }\end{array}$ & $\begin{array}{l}\text { Compared physician } \\
\text { satisfaction, turnaround } \\
\text { time, and ED LOS Pre and } \\
\text { Post implementation of a } \\
\text { POC lab in the ED. The lab } \\
\text { ran tests for BG, uHCG, } \\
\text { urine dipstick, CK-mb, \& } \\
\text { troponin. }\end{array}$ & $\begin{array}{l}\text { Lab results turn around time } \\
\text { declined from an average } \\
\text { time of } 59.5-8 \text { min. LOS } \\
\text { decreased by an average of } \\
41.3 \text { min, from average } \\
\text { LOS of } 389 \text { min }\end{array}$ \\
\hline Murray et al. [4] & $N=180$ & $\begin{array}{l}\text { Compared POC } \\
\text { testing vs lab } \\
\text { testing to see } \\
\text { effect on ED } \\
\text { LOS }\end{array}$ & $\begin{array}{l}\text { Patients seen in the ED at a } \\
\text { tertiary care teaching } \\
\text { hospital on } 12 \text { randomly } \\
\text { selected days from } 1995 \text { to } \\
1996 \text { who were suitable for } \\
\text { POC }\end{array}$ & $\begin{array}{l}\text { Randomized, controlled } \\
\text { study }\end{array}$ & $\begin{array}{l}\text { Significant shorter stay for } \\
\text { those DC, but not for those } \\
\text { admitted }\end{array}$ \\
\hline Ryan et al. [22] & $N=2000$ & $\begin{array}{l}\text { POC testing } \\
\text { effect on ED } \\
\text { LOS in ACS } \\
\text { patients } \\
\text { across } 4 \text { EDs } \\
\text { in US }\end{array}$ & $\begin{array}{l}\text { Patients over } 21 \text { years old } \\
\text { presenting with symptoms } \\
\text { suggestive of ACS and } \\
\text { having cardiac biomarker } \\
\text { tests ordered by the ED } \\
\text { physician }\end{array}$ & $\begin{array}{l}\text { Multicenter, randomized, } \\
\text { parallel-group trial }\end{array}$ & $\begin{array}{l}\text { With LOS = time of } \\
\text { departure from ED, either } \\
\text { to home or inpatient setting, } \\
\text { the result for LOS varies, } \\
\text { POC testing decreased time } \\
\text { to admission at one site but } \\
\text { increased time to DC at } \\
\text { another }\end{array}$ \\
\hline
\end{tabular}

$E D$ Emergency department, POC Point-of-care, LOS Length of stay, DC discharge, VTE Venous thromboembolism, ACS Acute coronary syndrome, $B G$ Blood glucose, Uhcg Urine human chorionic gonadotropin, $C K-m b$ Creatine kinase-mb

$83 \%$ [9]. The mean POC TAT was 15 min compared with a lab TAT of 90 min with a mean ED length of stay (LOS) of $3 \mathrm{~h}$ and $6 \mathrm{~min}$ [9]. The study concluded that the POC D-dimer machine is an effective and safe screening tool, which can be implemented in EDs [9]. Lee-Lewandrowski et al. [10] found that the implementation of a POC testing laboratory in the ED led to faster test TAT for blood glucose, urine human chorionic gonadotropin, urine dipstick, creatine kinase-MB, and troponin tests. This also led to a decreased LOS in the ED, and improved clinician satisfaction with test accuracy and TAT.

\section{Literature Review for Critical Pathway or Guideline}

Waller et al. [11] determined that an integrated care pathway for DKA resulted in significant improvements in time to initiation of intravenous fluids [45.0 (5-225) to 37.5 $(0-135) \mathrm{min} ; p=0.01]$, time to initiation of insulin [60.0
(5-755) to $37.5(0-175) \mathrm{min} ; p=0.02]$, and reduction in inappropriate antibiotic prescriptions $(48-18 \% ; p=$ 0.028).

Devalia and colleagues discovered that protocol-driven DKA management led to appropriate fluid resuscitation in $80 \%$ of patients, and appropriate insulin administration in $72 \%$ of patients. They also found that clinicians followed the DKA protocol during the first hour of treatment [12].

Bull et al. [13] assessed the effect of a mandatory protocol for ICU DKA management at an academic medical center. The protocol was implemented by means of education and an order set that provided orders for the nurse to manage patient monitoring, fluid resuscitation, insulin and dextrose infusion, and electrolyte repletion. Implementation of a mandatory, comprehensive protocol for treating DKA led to a shortened intensive care unit (ICU) LOS by $23 \%$ and hospital LOS by $30 \%$. Patients treated with the protocol also had a shorter time to clearance of the anion gap and ketones with no difference in the number of 


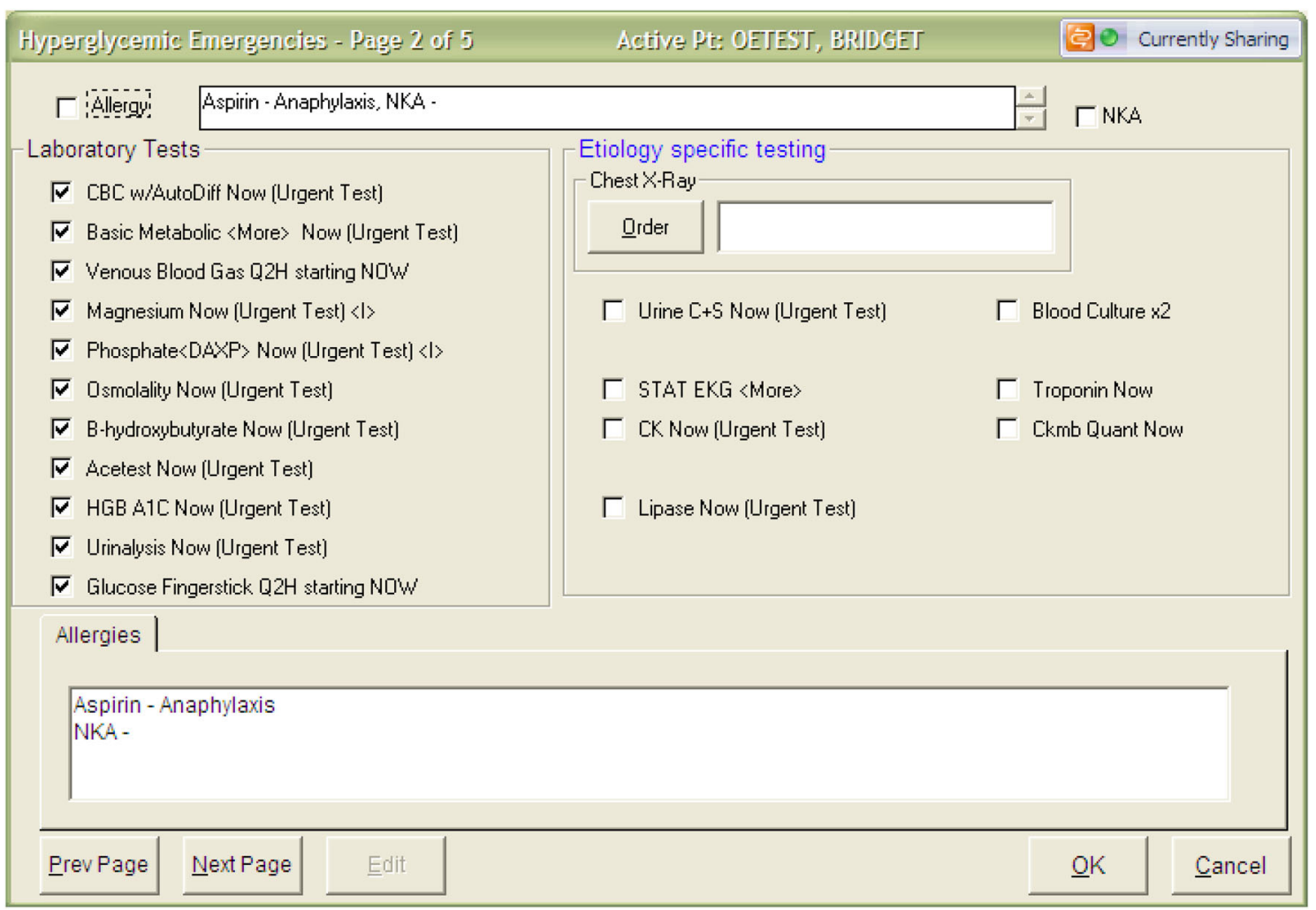

Fig. 1 POC glucose testing used as part of the hyperglycemic emergencies order set in the ED, Legend: **POC glucose testing

hypoglycemic episodes before and after implementing the protocol [13].

A study by Beik and colleagues implemented an institution-wide guideline for both DKA and HHS and provided education to various disciplinary groups to ensure the wide spread use of the guideline and order sets for patients presenting with DKA or HHS. This education component was ongoing throughout their study to ensure continued use of the guideline and order sets [14*0]. Additionally, continuous quality improvement metrics are needed to improve guideline utilization and adherence. This ensures that any feedback or updates to improve current guidelines will be addressed [14*0].

With the use of POC testing, timely identification and proper management of these hyperglycemic emergencies are essential to improve patient outcomes and provide good quality care. Beik and colleagues included all adult patients with a diagnosis of DKA and HHS before and after implementation of an institutional guideline and order set and who were admitted to the ICU or inpatient step-down units. The investigators of the study utilized initial glucose readings from POC testing to quickly identify patients who may need further DKA or HHS management [14.•]. POC glucose testing was then used as part of the hyperglycemia protocol to monitor glucose trends (Fig. 1). They found improvements in ICU LOS $(64.8 \pm 19$ vs. $37.1 \pm 74.8 \mathrm{~h}$, $p<0.01)$ and laboratory assessments, including time to anion gap closure $(13 \pm 9$ vs. $9.3 \pm 7.4 \mathrm{~h}, p<0.01)$ [14••]. They also saw an increase in the number of patients who received the recommended guideline weight-based insulin bolus dose prior to initiation of insulin infusion, dextrose administration according to guideline, increased frequency of POC glucose testing, and the guideline recommended transition to subcutaneous insulin in the postguideline and order set implementation group [14••].

\section{Discussion}

Glucose POC testing in patients that present to the ED with suspicion of DKA or HHS is often utilized in our institution. In addition to timely glucose POC testing, patients presenting with hyperglycemic emergencies are initiated on a hospital wide hyperglycemic emergencies order set to guide providers through the appropriate treatment plan and monitoring parameters which include POC glucose testing.

In the 1970s and 1980s, early studies outlined the basis for current treatment strategies of DKA and HHS [15••]. The mainstays of management: hydration, insulin therapy, and correction of electrolyte abnormalities have remained unchanged in the past 10 years [15••]. The ADA has outlined best practices to treat both DKA and HHS and recommend fluid therapy to correct hypovolemia, insulin therapy to 
correct hyperglycemia, electrolyte repletion to correct electrolyte imbalances, and frequent laboratory monitoring to ensure successful resolution of DKA and HHS [16]. The ADA guidelines stress the importance of early recognition of these hyperglycemic crises, which lead to prompt initiation of intravenous hydration and appropriate insulin management [16]. Despite these recommendations, research has shown variations in practice and low adherence with clinical guidelines resulting in suboptimal DKA management [17, 18]. Several published studies have advocated the use of treatment protocols to improve DKA management [11-13, $14 \cdot 0]$. These studies have shown to improve key modalities of DKA management, decrease time to resolution, as well as decrease length of stay (LOS) [11-13, 14••].

Recent evaluations of glucometers have shown POC testing devices to read within a $12.5 \%$ window $98.8 \%$ of the time when compared to venous puncture labs when glucose was $\geq 100 \mathrm{mg} / \mathrm{dl}[19 \bullet \bullet]$. When blood glucose was less than $100 \mathrm{mg} / \mathrm{dl}, 99.8 \%$ were within a $20 \%$ margin [19••]. Newer glucometers may have sufficient accuracy to be used and considered reliable in the emergency department. Most glucometers are able to read values between a range of 0-600 mg/dl, but may have slight variations [19••].

Our literature review found that POC testing in the ED leads to faster TAT of critical results which aid clinical decisions and leads to a decreased LOS in the ED. When POC testing is implemented for patients presenting with a suspected hyperglycemic emergency, this is a rapid, accurate, and easy-to-use screening tool which also yields a quicker TAT of results and therefore, quicker decisionmaking for clinicians.

\section{Protocol or Guideline Implemented Care}

Appropriate identification of patients experiencing a hyperglycemic crisis can provide medical staff with the necessary tools to implement correct treatment algorithms. Long laboratory TAT can contribute to a delay in initiating therapy. Therefore, the need for timely lab measurements, such as POC testing can help expedite critical laboratory results leading to appropriate initiation of treatment protocols or guidelines. This is seen in the study by Beik et al. as POC testing is the initial critical laboratory result that leads clinicians to utilizing the hyperglycemic emergencies management order set in the ED. Additionally, with the use of the order set, which has POC testing every $2 \mathrm{~h}$, they saw an increase in the frequency of POC testing in the POST group. With the routine use of POC testing, patients can be appropriately identified then quickly initiated on a treatment guideline that will standardize patient care in the ED.

Decision support tools are intended to deliver consistent patient care derived from evidence-based data. Decision support at the POC is crucial because they provide clinicians with specific instructions to assist in clinical decisions. Although the uses of guidelines and protocols have been shown to be effective, concerns about the threat to clinical judgment or differences in practice may be present.

Variability between clinicians is expected given diverse educational and practical backgrounds [20]. Given theses differences, protocols can prove useful in these situations when judiciously implemented to reduce inter-provider variability. Having protocols in place offers clinicians a tool that increases the likelihood that therapies are not overlooked or are implemented as intended. Most importantly patient safety may be enhanced due to consistent provider-to-provider transitions [21].

Additional benefits to implementing institution-wide protocols for clinicians may include quick adoption of new evidence to the bedside, consistent patient care, educational support, improvements in communication, cost avoidance, and improvement in patient safety. The caveat to protocolized care is that they are initialized for the appropriate patient. Many protocols are derived from large studies with specific patient populations and clinical judgment should take into account determining if a patient is an appropriate candidate for a treatment protocol $[20,21]$.

Clinicians should expect protocols within their own institutions to emphasize a multidisciplinary team-based approach with implementation by the proper identification of patients and incorporation of clinical decision-making tools. By implementing protocols that maintain clinician independence but minimize prescribing inconsistencies, care is more efficiently and effectively directed to improve patient outcomes.

\section{Conclusion}

POC testing allows results to be available immediately and relayed to all members of the medical team instantaneously and decreases TAT. Rapid provision of results may facilitate better clinical decision-making, appropriate use of clinical guidelines, which will lead to improved clinical outcomes.

Acknowledgments The authors acknowledge the contributions of PharmD candidates Ha Nguyen and Kevin Day in the preparation of this manuscript.

\section{Compliance with Ethics Guidelines}

Conflict of Interest The authors have declared no conflicts of interest.

Human and Animal Rights and Informed Consent This article does not contain any studies with human or animal subjects performed by any of the authors. 


\section{References}

Papers of particular interest, published recently, have been highlighted as:

•- Of major importance

1. Nyenwe EA, Kitabchi AE. Evidence-based management of hyperglycemic emergencies in diabetes mellitus. Diabetes Res Clin Pract. 2011;94:340-51.

2. Wang ZH, Kihl-Selstam E, Eriksson JW. Ketoacidosis occurs in both Type 1 and Type 2 diabetes-a population based study from Northern Sweden. Diab med. 2008;25:867-70.

3. Kitabchi AE, Nyenwe EA. Hyperglycemic crises in diabetes mellitus: diabetic ketoacidosis and hyperglycemia hyperosmolar state. Endocrinol Metab Clin North Am. 2006;35:725-51.

4. Murray RP, Leroux M, Sabga E, Palatnick W, Ludwig L. Effect of point care testing on patients length of stay in a large emergency department. J Emerg Med. 1999;17:811-4.

5. Lee JH, Kim K, Jo YH, et al. Feasibility of continuous glucose monitoring in critically ill emergency department patients. J Emerg Med. 2012;43:251-7.

6. Charles RA, Bee YM, Eng PH, Goh SY. Point-of-care blood ketone testing: screening for diabetic ketoacidosis at the emergency department. Singap Med J. 2007;48:986-9.

7. Arora S, Henderson SO, Long T, Menchine M. Diagnostic accuracy of point-of-care testing for diabetic ketoacidosis at emergency-department triage. Diabetes Care. 2011;34:852-4.

8. Arora S, Probst MA, Agy C, Menchine M. Point-of-care betahydroxybutyrate testing for assessing diabetic ketoacidosis severity prior to treatment in the emergency department. Diabetes Res Clin Pract. 2011;94:86-8.

9. Sen B, Kesteven P, Avery P. Comparison of D-dimer point of care test against current laboratory test in patients with suspected venous thromboembolism presenting to the emergency department. J Clin Pathol. Dec 2013; [Online].

10. Lee-Lewandrowski E, Corby D, Lewandrowski K, et al. Implementation of a point-of-care satellite laboratory in the emergency department of an academic medical center. Arch Pathol Lam Med. 2003;127:456-60.

11. Waller SL, Delaney S. Does an integrated care pathway enhance the management of diabetic ketoacidosis? Diabet Med. 2007;24:359-63.

12. Devalia B. Adherence to protocol during the acute management of diabetic keto- acidosis: would specialist involvement lead to better outcomes? Int J Clin Pract. 2010;64:1580-2.
13. Bull SV, Douglas IS, Foster M, Albert RK. Mandatory protocol for treating adult patients with diabetic ketoacidosis decreases intensive care unit and hospital lengtsh of stay: results of a nonrandomized trial. Crit Care Med. 2007;35:41-6.

14. • Beik N, Anger KE, Forni AA, Bawa K, Szumita PM. Evaluation of an institution-wide guideline for hyperglycemic emergencies at a tertiary academic medical center. Ann Pharmacother. 2013;47:1260-1265. This analysis showed implementation of and institutional hyperglycemic emergency guideline in the ED shortened ICU LOS.

15. • Steenkamp DW, Alexanian SM, McDonnell ME. Adult hyperglycemic crisis: A review and perspective. Curr Diab Rep. 2013; 13:130-137. This article provides the background for identification and appropriate treatment of patients with DKA and HHS which include fluid, electrolyte, and insulin management.

16. Kitabchi AE, Umpierrez GE, Murphy MB, et al. Hyperglycemic crises in diabetes. Diabetes Care. 2004;27(suppl 1):S94-102.

17. Singh RK, Perros P, Frier BM. Hospital management of diabetic ketoacidosis: are clinical guidelines implemented effectively? Diabet Med. 1997;14:482-6.

18. Sola E, Garzon S, Garcia-Torres S, Cubells P, Morillas C, Hernandez-Mijares A. Management of diabetic ketoacidosis in a teaching hospital. Acta Diabetol. 2006;43:127-30.

19. • Joseph JI. Analysis: New point-of-care blood glucose monitoring system for the hospital demonstrates satisfactory analytical accuracy using blood from critically ill patients - an important step toward improved blood glucose control in the hospital. J Diabetes Sci Technol. 2013; 7(5): 1288-1293. This article highlights the accuracy and effectiveness of point-of-care blood glucose monitoring. Glucose monitor measurements were compared with venous blood glucose measurements and were found to be accurate. Optimization of glucose meters may improve insulin delivery.

20. Morris AH. Treatment algorithms and procolized care. Curr Opin Crit Care. 2003;9:236-24.

21. Holcomb BW, Wheeler AP, Ely EW. New ways to reduce unnecessary variation and improve outcomes in the intensive care unit. Curr Opin Crit Care. 2001;7:304-11.

22. Ryan RJ, Lindsell CJ, Hollander JE, et al. A multicenter randomized controlled trial comparing central laboratory and pointof-care cardiac marker testing strategies: the disposition impacted by serial point of care markers in acute coronary syndromes trial (DISPO-ACS) trial. Ann Emerg Med. 2009;53:321-8. 